\title{
METHODS AND CRITERIA FOR SELECTING THE SUITABLE MATERIALS TO ACHIEVE THE NEW BALLISTIC PROTECTION VEST DESIGNED TO WOMENS
}

\author{
Simona Maria BADEA, Claudiu LĂZĂROAIE, \\ Teodora ZECHERU, Ioana LAZĂR, \\ Scientific Research Center for CBRN Defense and Ecology, Bucharest, Romania \\ smsbadea@yahoo.com
}

\begin{abstract}
Women's participation in the activities, which were limited only for men in the past, has increased over the years. Since women are not in the majority, the protective equipment they wear has not been developed for their use.

In our project, we are intending to identify the available materials and technologies to produce new composite materials for ergonomic ballistic protection equipment for women from national defense system, in the respect of providing better fit and mobility to the wearer. The main goal of the project is to apply a design and materials that offers more comfort to the wearers (female soldiers) using the best available technologies and materials.

This paper presents the methods and the criteria to select the best materials suitable for achieving a new ballistic protection vest designed especially for women from national defense system, in order to meet the requirements regarding the protection against ballistic threats and the comfort demands too.
\end{abstract}

Keywords: ballistic protection, body armor, impact resistance

\section{Introduction}

Ballistic protection refers to the totality of techniques adopted in order to provide protection to personnel (and materiel) against projectiles of all kinds. The equipments for ballistic protection provided to personnel are generally known as bullet proof vests or body armors.

The function of body armor is to provide protection in terms of decreasing impact and preventing penetration from weapons. However, as weapons have advanced, it is almost impossible to use only one kind of protective equipment to prevent injury. The body armors, today, are produced in many styles and types to more efficiently perform their functions.

Women's participation in the activities, which were limited only for men in the past, has increased over the years. More and more women are employed in physically rigorous jobs, like being soldiers and firefighters. According to an US Army News Report issued in January 2011, 14 \% of the active-duty military personnel are females. In other words, for every seven soldiers, one will be a female. These jobs are meaningful and responsible, but many of them are dangerous.

Since women are not in the majority, the protective equipment they wear has not been developed for their use. Historically, all the uniforms and the protective gears designed for military or paramilitary personnel were designed considering the male sizes. Plus, most manufacturers design the protective equipment for specific danger and not for the wearer. 
Women in the military are ordered to wear the body armors that fail to fit them, but, as the project manager of US program of body armor for female soldiers said "women are not small men".

\section{General information concerning body armors}

Generally, body armors consist of two parts, the protective panel and the carrier. The protective panel is constructed by layers of the ballistic-resistant materials. These layers can be all the same sort of material or different materials and will be laminated together to achieve a certain level of protection. The carrier is made of regular garment fabrics, such as woven nylon. The protective panel can be inserted or sewn into the carrier. The performance and properties of the body armor depend on the location and number of layers of the protective panel.

Comfort is mainly relative with the number of fabric layers and materials of the protective panel. It is the ultimate goal for the manufactures of ballistic protection equipment to achieve the maximum protection and comfort with the minimum weight.

The contribution of the protective garment to survivability is pronounced. According to a US National Institute of Justice report issued in 2006, three thousand US law enforcement officers lives have been saved by their body armor in the last 30 years. Police officers don't wear their vest all the time unless they are on duty. However, soldiers in the battle are asked to wear the protective equipment all the time. The types of ballistic vests for law enforcement officers are not the same as the army because the levels of the threats that they encounter are different.

Besides the level of ballistic protection, comfort is the biggest problem. Officers' performance can be affected by the level of comfort while wearing the vests. If the regular ballistic vest can't provide adequate comfort, it is not hard to imagine how uncomfortable the soldiers are when they wear the vests with additional plates.
Actual studies, carried out by US Department of Defense (DoD), revealed that when it is worn by a woman, a gap between breasts and the front panel is created and the gap can be big enough to stick a grenade inside and are an extra danger for the female soldiers. The size extra-small is too loose or too large for $85 \%$ of the female soldiers. Moreover, it is difficult to breathe as a result of the pressure from the front panel in the bust area. These factors raise the risk of battle injuries while women are wearing this kind of body armor.

There are several properties of body armors that define them. Impact resistance and comfort, like fit and mobility, are the common and primary needs of the wearers of body armors.

Impact resistance. To protect the body from the strong impact generated by bullets or fragments is one of the primitive ideas of inventing body armors. Generally, people think the function of the body armor is preventing bullets or fragments from penetrating the human body. However, some recent researches and statistics have shown that blunt trauma caused by the impact of the bullets can cause fatal injury as well. It can cause severe internal damages or bruises and even death. Body armors, especially the one with rigid material, should be able to perform at least the following three protective functions: first, spread the impact, second, prevent penetration, and third, absorb energy. Scientists and ballistic equipment manufacturers are also engaged in creating new material having better and quicker manner to spread the impact and absorb the energy.

Comfort ( Fit \& Mobility). Comfort is defined as a broad and abstract concept as well as a narrow and subjective one. It can represent either physical or psychological feeling. The standards that people identify their comfort level are varied. Therefore, it is always the hardest respect for designers to cope with. Although the ballistic vest has been saving thousands of police officer's 
lives, 40 percent of police officers still do not wear body armor because of its discomfort. The reason is that the discomforts, like fit and dissipation problems, affect their performance while wearing the vests.

Body armors must be worn to be effective. Weight, mobility, and comfort therefore are vital to ensuring their use; the armors must conform to the user's body, properly distribute their weight over the body to minimize user fatigue, provide sufficient breathability for extended use - especially during high temperatures, and must not interfere with or restrict the user's mobility. The significant challenge is to balance the level of protection required for specific threat type(s) against weight, comfort and flexibility, cost, environmental exposure (heat, ultraviolet light, moisture, etc.), and service life.

\section{Suitable materials}

Soft body armor with adequate ballistic protection is preferred due to their flexibility, lightweight and comfort properties. Several researches on soft body armor have investigated the behavior of fibers, yarns and fabrics during ballistic impacts. In addition to the fiber type and its performance, the degree of ballistic protection depends on the yarn properties, fabric construction, and the number and type of layers used in the structure. The type of bullet (figure 1), bullet geometry, velocity and impact angle also affect the protection level of soft body armor.

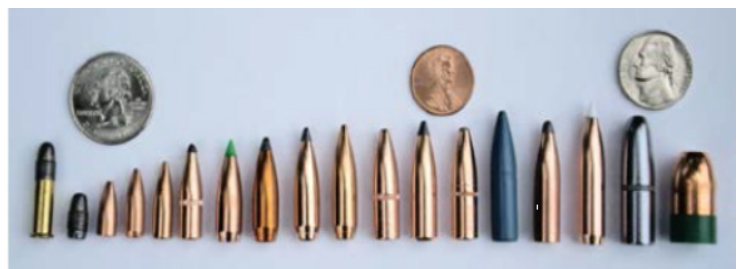

Figure 1 Typesof ammunitions (bullets)

The fibers used for ballistic protection should have: low density, high strength and high energy absorption capability. The ballistic performance of a material depends on its ability to absorb energy locally and to distribute it across a whole structure. For textile fibers, the tenacity and elongation at rupture, the sonic velocity (the velocity of sound in textile) of the fibers are important parameters determining the protection that they can provide. Recent body armor designs use fibers such as aramid (Kevlar ${ }^{\circledR}$, Twaron ${ }^{\circledR}$ and Technora $\left.{ }^{\circledR}\right)$, high performance polyethylene (HPPESpectra ${ }^{\circledR}$ and Dyneema $\left.{ }^{\circledR}\right)$, poly $(\mathrm{p}$ phenylene-2,6-benzobisoxazole) (PBOZylon $\left.{ }^{\circledR}\right)$, and high strength nylon.

Table 1 Detailed information on the textile fibers used for ballistic protection [1]

\begin{tabular}{|c|c|c|c|}
\hline Fibre name & Type & Company & Chemical structure \\
\hline Kevlarß & p-aramid & DuPont & \\
\hline Twaron (8) & p-aramid & $\begin{array}{l}\text { Akzo } \\
\text { Nobel } \\
\text { (now } \\
\text { Teijin) }\end{array}$ & \\
\hline Technora $\mathbb{R}$ & p-aramid & Teijin & \\
\hline Specta $\mathbb{R}$ & HPPE & $\begin{array}{l}\text { Allied } \\
\text { Signal } \\
\text { (now } \\
\text { Honeywell }\end{array}$ & \\
\hline Dyneema $®$ & HPPE & $\begin{array}{l}\text { DSM and } \\
\text { Toyobo }\end{array}$ & \\
\hline Zylon® & PBO & Toyobo & \\
\hline $\begin{array}{l}\text { Ballistic } \\
\text { Nylon } \\
\text { (Nylon 6-6) }\end{array}$ & Polyamide & DuPont & \\
\hline M5ß & $\begin{array}{l}\text { Polyhydro } \\
\text { quinone- } \\
\text { diimidazo } \\
\text { pyridine }\end{array}$ & $\begin{array}{l}\begin{array}{l}\text { Akzo } \\
\text { Nobel } \\
\text { (now }\end{array} \\
\text { Magellan } \\
\text { Systems } \\
\text { Intemation } \\
\text { al) }\end{array}$ & \\
\hline
\end{tabular}

\section{Test methods}

Current soft body armors used for ballistic protection are worn to protect the torso and extremity regions; they are developed in conjunction with rigorous standards and specifications to ensure proper performance and reliability levels against ballistic and fragment threats. For example, the National Institute of Justice (NIJ) prepared the "Ballistic Resistance of Body Armor NIJ Standard-0101.06"[2] to categorize ballistic threats including projectile types, sizes, and velocities; establish deformation limits; develop sample conditioning protocols; and specify acceptance testing procedures for body armors.

Ballistic testing of military armors for personnel, vehicles, and other systems subject to small arms munitions is governed by Military Standard MIL-STD-662F [3]. 
Fragment testing of military personnel armors resulting from fragmenting munitions, such as grenades and mortar rounds, is performed in accordance with the North Atlantic Treaty Organization (NATO) Standardization Agreement (STANAG) 2920.[4]

Acceptance testing of soft armors determines their ballistic limit velocities for prescribed projectiles, projectile velocities, and angles of incidence. A variety of ballistic limit velocities are defined with each having a statistical significance. These include the $V_{0}, V_{50}$, and $V_{100}$ ballistic limit velocities and are designated as the maximum velocity at which no complete penetration will occur, the velocity at which a $50 \%$ probability of complete penetration will occur, and the minimum velocity at which $100 \%$ probability of complete penetration will occur, respectively. Ballistic tests are performed on both dry and wet body armors by firing a number of projectiles at prescribed locations apart from each other, at angles of incidence of $0^{\circ}$ (normal) and $30^{\circ}$ (oblique), at seams, and at specific distances from the edges. Testing has shown that ballistic limit velocities are proportional to the areal weight density of the woven fabrics.

Although soft body armors are used to prevent penetration by specified small arms projectiles, deformations in the form of indentations can occur to the extent that further life-threatening injuries remain possible. Impact deformation limits are often specified to help minimize indentation depths, which are also known as BFSs. The NIJ standard [2] specifies a maximum BFS of $44.0 \mathrm{~mm}$ (1.73 inches). BFSs, as shown in figure 2, may lead to blunt trauma injury, which is also known as behind-armor-blunttrauma (BABT). Serious injury to tissues, skeletal structures, and organs can occur and may be fatal. Blunt trauma may not be immediately detected-it may manifest itself at a later time and can be damaging to organs remote from the impact site depending on the propagation of stress waves into the body

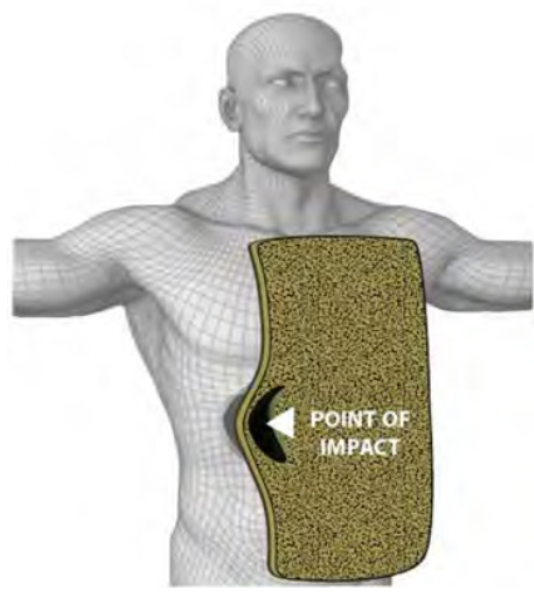

Figure 2 Blunt Trauma Resulting from Excessive Impact Deformation

BFS measurements are made during ballistic testing of vests backed with oilbased modeling clay known as Roma Plastilina No. 1. This clay has mass properties similar to those of a human body and does not spring back after ballistic impact - a key feature for locking-in the indentation depth for measurement purposes, as shown in figure 3 .
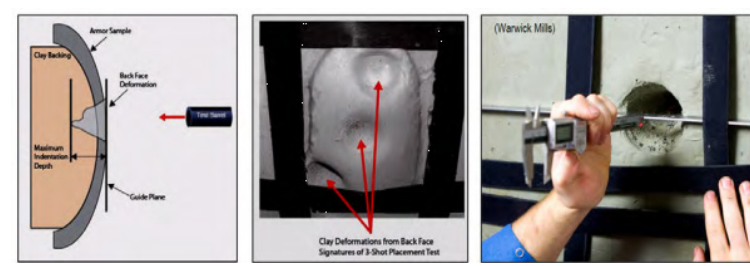

Figure 3 Clay-Backed Ballistic Testing and BFSs

\section{Conclusions}

In this project, we are intending to identify the available materials and technologies (not necessarily commercial but with a certain level of technological readiness) to produce new composite materials for an ergonomic ballistic protection equipment for women from national defense system, in the respect of providing better fit and mobility to the wearer. The main goal of the project is to apply a design and materials that offers more comfort to the wearers (female soldiers) using the best available technologies and materials.

Suitable materials have to fullfill some properties like flexibility, lightweight and 
comfort. Also, the most important feature is the ability to provide ballistic protection against bullets and fragments.

Ballistic tests are performed based on most used international standards.

The work plan of the project will be developed so that we will combine materials and technologies to obtain a ballistic panel with at least the same ballistic protection properties as the actual bulletproof vests, but with an increased ergonomics and comfort, in order to produce a ballistic protection bullet proof vest designed especially for women from national defense system. By achieving our goal we will deliver a product that will increase the protection level and the survivability of the target group (female soldiers)

\section{Acknowledgement}

This work was realized under the Program "Partnerships in priority areas - PNII", developed with the support of UEFISCDI, project Ergonomic ballistic protection equipment for female staff of the national defense system structures, contract no. 303/2014.

\section{References}

[1] L Wang, S Kanesalingam, R Nayak and R Padhye, Recent Trends in Ballistic Protection Textiles and Light Industrial Science and Technology (TLIST) Volume 3, 2014

[2] "Ballistic Resistance of Body Armor," NIJ Standard-0101.06, National Institute of Justice, July 2008.

[3] "V50 Ballistic Test for Armor," MIL-STD-662F, Department of Defense Military Standard, December 1997

[4] "Ballistic Test Method for Personal Armour Materials and Combat Clothing" NATO Standardization Agreement (STANAG) 2920, Edition 2, 2003. 